\title{
METAMORFORSES DO EU: ESTUDANTES RURAIS NAS ESCOLAS URBANAS
}

\author{
METAMORPHOSES OF THE SELF: \\ RURAL STUDENTS ON URBAN SCHOOLS
}

\author{
METAMORFOSIS DEL YO: \\ ESTUDIANTES RURALES EM LAS ESCUELAS URBANAS
}

\section{Elizeu Clementino de Souza ${ }^{l}$ Hanilton Ribeiro de Souza ${ }^{2}$ Nanci Rodrigues Orrico}

\begin{abstract}
RESUMO: Emergindo da interlocução entre as questões que nos mobilizam como pesquisadores e as reflexões sobre educação, ruralidades e modos de subjetivação suscitados no âmbito do projeto de pesquisa e inovação educacional "Multisseriação e trabalho docente: diferenças, cotidiano escolar e ritos de passagem" (GRAFHO/ UNEB), o texto sistematiza reflexões sobre dois subprojetos que dialogam sobre as metamorfoses que os estudantes de escolas rurais baianas vivenciam no rito de passagem para as escolas urbanas, face às expectativas e desafios que os jovens experimentam, buscando apreender modos como vivenciam essa transição e se reconhecem como sujeitos desse processo. Para entender a dinâmica referida, apoiamo-nos metodologicamente na abordagem (auto)biográfica, adotando as entrevistas narrativas como dispositivos de pesquisa (SCHUTZE, 2010) e nos estudos de Delory-Momberger (2012), Nóvoa e Finger (2014) e Souza (2006, 2008, 2011a) a partir da sistematização de princípios teóricos sobre a abordagem (auto)biográfica construídos pelos autores. Do mesmo modo, o texto toma como referência contribuições de Souza $(2011 \mathrm{~b}, 2012)$ e Rios (2011a), no que se refere às discussões sobre ruralidades e multisseriação e também de Guattari e Rolnik (1999), Foucault (1997) e Guattari (1993), no que concerne às discussões sobre subjetividade, biopolítica e modos de subjetivação na sociedade contemporânea. Os resultados apontam para a necessidade de novos olhares para as práticas pedagógicas desenvolvidas nas escolas urbanas, de modo que estas tenham maior vinculação com a identidade rural dos estudantes e sejam mais significativas, promovendo uma educação emancipatória, para além dos ditames do mercado.
\end{abstract}

PALAVRAS-CHAVE: Ruralidades. Modos de subjetivação. Escolas rurais/do campo.

ABSTRACT: Emerging from the interlocution between the issues that mobilize us as researchers and the reflections on education, ruralities and ways of subjectivity raised within the research Project and educational innovation "Multigrade and teaching profession: differences, everyday school life and rites of passage" (GRAFHO / UNEB), the text systematized reflections on two subprojects that dialogue on metamorphoses that students from Bahia rural schools experience in the rite of passage for urban school, facing the expectations and challenges that young people experience in joining the city's schools, seeking to understand ways they

\footnotetext{
${ }^{1}$ Doutorado em Educação pela Universidade Federal da Bahia (2014). Membro do Conselho de Administração da Associação Internacional das Histórias de Vida em Formação, França. E-mail: esclementino@uol.com.br.

${ }^{2}$ Mestrado em Cultura, Memória e Desenvolvimento Regional pela Universidade do Estado da Bahia (2008). Membro do Grupo de Pesquisa GEO(BIO)GRAFAR da Universidade do Estado da Bahia. E-mail: hrsouza@uneb.br.

3 Mestranda em Educação e Contemporaneidade pela Universidade do Estado da Bahia. Professora da Faculdade Regional de Filosofia, Ciências e Letras de Candeia, Bahia. E-mail: nanciorrico@ hotmail.com.

Recebido em: 08/07/2015 - Aprovado em: 21/10/2015.
} 
experience this transition and recognize themselves as subjects of this process. To understand the referred dynamics, we support methodologically on the (auto) biographical approach, adopting the narrative interviews as research devices (SCHUTZE, 2010) and studies of Delory-Momberger (2012), Nóvoa and Finger (2014) and Souza ( 2006, 2008, 2011a) from the systematization of theoretical principles on the (auto) biographical approach constructed by the authors. Likewise, the text takes as reference contributions from Souza (2011b, 2012) and Rios (2011a), regarding discussions of ruralities and multigrade and also in Guattari and Rolnik (1999), Foucault (1997) and Guattari (1993) in what concerns to discussions of subjectivity, biopolitics and ways of subjectivity in contemporary society. The results point to the need of new glances for pedagogical practices developed in urban schools, so that they have closer links with the rural identity of students and are more meaningful, promoting an emancipatory education, beyond what the market dictates.

KEYWORDS: Ruralities. Modes of subjectivity. Rural/Country schools.

RESUMEN: Emergiendo de la interlocución entre las cuestiones que nos movilizan como investigadores y los debates sobre educación, ruralidades y modos de subjetivación suscitados en el proyecto de investigación e innovación educativa "Multisseriação e trabalho docente: diferenças, cotidiano escolar e ritos de passagem" (GRAFHO/ UNEB), el texto sistematiza reflexiones de dos subproyectos que dialogan sobre la metamorfosis que los estudiantes de las escuelas rurales de Bahía experimentan durante el rito de pasaje hacia la escuela urbana y frente a las expectativas y desafíos que enfrentan en su ingreso a las escuelas de la ciudad. El trabajo busca comprender las formas en que los jóvenes de zonas rurales vivencian esta transición y se reconocen a sí mismos como sujetos de este proceso. Para avanzar en el entendimiento de esta dinámica, nos apoyamos metodológicamente en el enfoque (auto) biográfico, adoptando las entrevistas narrativas como dispositivos de investigación (SCHÜTZE, 2010) y los estudios de Delory-Momberger (2012), Novoa y Finger (2014) y Souza (2006 2008, 2011a), a partir de la sistematización de los principios teóricos del enfoque (auto) biográfico construido por los autores. Asimismo, el texto refiere a las contribuciones de Souza (2011b, 2012) y Ríos (2011a) en relación con las discusiones sobre ruralidades y multiseriación, y también a las de Guattari y Rolnik (1999), Foucault (1997) y Guattari (1993) en lo que concierne a las discusiones sobre la subjetividad, la biopolítica y modos de subjetivación en la sociedad contemporánea. Los resultados apuntan a la necesidad de construir una nueva mirada sobre las prácticas pedagógicas desarrolladas en las escuelas urbanas, de modo que éstas tengan mayor vinculación con las identidades rurales de los estudiantes y sean más significativas para ellos, promoviendo una educación emancipadora, más allá de los dictados del mercado.

PALABRAS CLAVE: Ruralidades. Modos de subjetivación. Escuelas rurales/del campo.

\section{QUESTÕES INICIAIS: DESLOCAMENTOS, TRÂNSITOS E PROCESSOS DE ESCOLARIZAÇÃO}

As últimas décadas do século XX são marcadas por intensas transformações na educação. Entre elas, ressaltamos a expansão do Ensino Médio público no Brasil, especialmente nas cidades médias e pequenas, locais nos quais tal nível era, originalmente, acessível, quando existia, apenas as elites locais, por meio de escolas particulares e/ou religiosas. Com a ampliação do sistema público de ensino e, consequentemente, o aumento das matrículas neste nível educacional, houve o acesso de um novo público, mais popular e plural, às escolas secundárias, entre eles os alunos e alunas egressos das escolas da roça.

Nesse sentido, nos perguntamos: Será que a escola estava (e está) preparada para acolher e desenvolver atividades para um público tão diverso, especialmente respeitando as diferenças e as especificidades de cada indivíduo, seja ele da periferia da cidade ou da zona rural? Esses e outros questionamentos têm sido feitos por professores e pesquisadores integrantes da equipe do projeto de pesquisa e inovação educacional "Multisseriação $e$ 
trabalho docente: diferenças, cotidiano escolar e ritos de passagem (SOUZA, 2013) ${ }^{i}$ ", que objetiva minimizar processos de exclusão sofridos por estudantes de escolas rurais na passagem para escolas urbanas e elaborar materiais e propostas pedagógicas que acolham suas especificidades.

Reconhecendo a necessidade de um olhar sensível sobre a delicada teia da vida de cada aluno, respeitando e valorizando as especificidades de cada ser, suas origens, expectativas e maneiras de ser e viver, percebemos o quanto os sujeitos provenientes da zona rural têm sido invisibilizados. Suas ruralidades - que são as especificidades, o cotidiano e as vivências do rural (SOUZA, 2011b e 2012; RIOS, 2011a), não são valorizadas e, na maioria das vezes, essa identidade rural é suplantada para criação de uma identidade considerada mais adequada à escola e à vida na cidade, com todas suas demandas criadas para atender a sociedade urbana do consumo.

Neste trabalho, destacamos nossa opção em discutir o Ensino Médio e as ruralidades, ou seja, como os alunos da roça, com suas maneiras de ser, viver e apreender o rural, são recebidos, inseridos e formados no ambiente escolar urbano. Tal opção, segundo Souza (2011b, p. 15), "recai sobre possíveis articulações entre práticas escolares e território, como fatores que intervém no processo e nos resultados de qualquer escola, mesmo as situadas em regiões urbanas".

Com o objetivo de promover um debate sobre as metamorfoses que os estudantes de escolas rurais baianas vivenciam no rito de passagem para a escola urbana, apoiamo-nos metodologicamente na abordagem (auto)biográfica, adotando as entrevistas narrativas como dispositivos de pesquisa (SCHUTZE, 2010) e nos estudos de Dellory-Momberger (2012), Nóvoa e Finger (2014) e Souza (2006, 2008, 2011a), a partir da sistematização de princípios teóricos sobre a abordagem (auto)biográfica construídos pelos autores. Tal opção nos permitirá, por intermédio de escuta sensível e colaborativa, apreender anseios, expectativas e desafios que os jovens experimentam no ingresso em escolas da cidade, explicitando modos como vivenciam essa transição e se reconhecem como sujeitos desse processo. Nessa perspectiva, elegemos como questão norteadora: Até que ponto o ingresso dos jovens de escolas rurais nas escolas urbanas promovem uma metamorfose nestes estudantes, descaracterizando-os da sua identidade rural?

Dessa forma, o texto busca problematizar, além desta questão, outras relativas à territorialidade, pertencimento, identidade cultural, modos de subjetivação e biopolítica, em um entrelaçamento entre elementos que podem nos mostrar novos horizontes a serem trilhados pelos profissionais da educação que acolhem esses jovens rurais no ingresso nas escolas urbanas. O texto objetiva discutir questões relacionadas ao Ensino Médio e suas relações com as ruralidades por meio de uma cartografia sócio-histórica, bem como tematizar aspectos teóricos a partir de diálogos contemporâneos sobre juventudes rurais, ritos de passagem e homogeneização. Por fim, serão apresentados alguns aspectos sobre o lugar \begin{tabular}{l|l|l|l|l|l|l} 
(C) ETD - Educ. Temat. Digit. & Campinas, SP & v.17 & n.3 & p. 542-557 & set./dez.2015 & ISSN 1676-2592
\end{tabular} 
ocupado pelo Ensino Médio, ou seja, para além dos ditames do mercado e suas interfaces para o atendimento dos sujeitos que habitam em territórios rurais e vivem cotidianamente deslocamentos para escolas urbanas, tendo em vista a continuidade de seus processos de escolarização.

\title{
2 ENSINO MÉDIO E RURALIDADES: UM DEBATE NECESSÁRIO
}

Entendemos que atentar para a importância dos estudos sobre ruralidades pode proporcionar a compreensão de como se configuram os sujeitos, suas ações, o espaço, a instituição escolar e suas práticas pedagógicas/formativas (SOUZA, 2012). Por conseguinte, Rios também vem ratificar a importância dos estudos sobre ruralidades no mundo atual, ao afirmar que:

\begin{abstract}
Assim, as reflexões sobre a ruralidade na atualidade exigem o reconhecimento do rural, tanto nas suas relações com o urbano, como segundo as suas relações internas e específicas. A possibilidade de se estudar novas ruralidades supõe, portanto, a compreensão dos contornos, das especificidades e das representações desse espaço rural entendido, ao mesmo tempo, como espaço físico (referência à ocupação do território e aos seus símbolos), lugar onde se vive (particularidades do modo de vida e referência identitária) e lugar de onde se vê e se vive o mundo (a cidadania do homem rural e sua inserção nas esferas mais amplas da sociedade) (RIOS, 2011b, p. 79).
\end{abstract}

Compreendemos que as ruralidades trazem embutidas também a questão do território, à medida que os alunos da roça necessitam fazer a transição por diferentes territorialidades para estudar na zona urbana. Nesse sentido, tal trânsito e vivência em outros territórios, que possuem outras territorialidades, influencia, de certo modo, na vida dos indivíduos. E se tal território for a escola, há maior influência ainda, pois é nesse espaço que os alunos da roça se deparam com distintas práticas discursivas que irão negar suas identidades, legitimando e normalizando outras subjetividades e identidades.

Esse processo de trânsito diário entre territórios, vivenciado sobre outras territorialidades, acaba por criar desterritorializações físicas e simbólicas que vão influenciar na apreensão da realidade e na formação do sujeito. Todo esse processo de desterritorialização, segundo Santos (2012, p. 82), pode "significar alienação, estranhamento que são, também, desculturização". Porém, não se trata de uma desterritorialização permanente e sim pendular, movimento diário de ir e vir para a cidade, atravessar outros territórios: roça, estradas, cidade, praças, ruas, lanchonetes e escola, convivendo e aprendendo a se inserir em outras territorialidades. Sobre essa questão, enfatiza Rios (2011b, p. 92) que "estudar no movimento de 'lá' e 'cá', entre a roça e a cidade, delineia as ambivalências, movências e a fluidez na qual tais alunos e alunas vivem na constituição de seus saberes, discursos e identidades". 
Nessa perspectiva, discutir escola e ruralidades tem uma importância fundamental, especialmente para os professores que participam desse processo, e, muitas vezes, legitimam, com suas práticas, os desrespeitos e a invisibilidade dos alunos oriundos da roça, negando sua identidade e seus modos de ver e apreender o mundo. Além do mais, tal discussão também oportuniza repensar a escola e o ensino, como destaca Delory-Momberger, ao afirmar que:

\begin{abstract}
A experiência escolar apresenta vários aspectos complementares: de um lado, a escola, enquanto meio social organizado e especificado em suas tarefas e suas funções, entra em relação com uma história individual que tem sua origem antes dela e que prossegue depois dela, história que se declina num raio de determinações, de representações, de projeções coletivas e individuais; de outro lado, a própria escola é portadora de história: componente da história apresentada dos alunos, ela é também componente de sua história futura e vem interferir - pela seleção que opera, as orientações que determina, os modelos de percurso e de finalização que propõe -, nos desejos e projetos dos alunos e de suas famílias [...]. Sob esses diferentes aspectos que compõem a experiência subjetiva dos alunos, a escola está no centro de múltiplos jogos de representações na maneira como os alunos constroem para eles mesmos e pelos outros sua história e seu futuro (DELORY-MOMBERGER, 2012, p. 192-193).
\end{abstract}

Assim, na busca pela superação dos desrespeitos, da não valorização e da invisibilidade quanto às especificidades do outro, especialmente dos alunos da roça, é que acreditamos que a escola e seus professores necessitam repensar as práticas pedagógicas, buscando perceber, valorizar e aprender a utilizar tais singularidades para a produção do conhecimento, a fim de não comprometer a formação e o futuro do estudante, bem como o desenvolvimento do lugar, tendo em vista que esse processo depende da educação plena, reflexiva e cidadã, que deve ser ofertada pela escola para seus alunos, tão diversos e singulares ao mesmo tempo.

Segundo Assmann (2003, p. 119), "a pedagogia deve preocupar-se com diversificar as 'confluências possíveis' dos modos e formas de conhecer, e não impor pedagogicamente um único modelo de conhecimento". Porém, para isso, é necessário que a escola respeite, valorize e utilize as singularidades dos seus alunos, no caso específico daqueles provenientes do ambiente rural, para a produção autônoma, diversificada e reflexiva do saber. Trindade (2000) também nos alerta para tal ciclo de preconceito e invisibilidade existente em muitas escolas, ressaltando que é preciso perceber a criança e o jovem em sua essência, em relação à vida que eles representam e às infinitas possibilidades trazidas e existentes neles, a fim de que não destruamos a teia da vida que existe ali e comprometamos o seu futuro: "A gente educa (se é que se pode dizer assim) para uma morte em vida: a invisibilidade" (TRINDADE, 2000, p. 9).

Em se tratando do Ensino Médio, podemos afirmar que, apesar das tentativas de reformulação desde a implantação da Lei de Diretrizes e Bases da Educação (LDB 9394/1996), ainda observamos que muito caminho resta para que a escola se aproxime do aluno (seja na questão profissional, social ou pessoal) e do seu cotidiano, valorizando-os. Os 
Parâmetros Curriculares para o Ensino Médio enfatizam tal necessidade: "Na escola atual, as perspectivas profissional, social ou pessoal dos alunos não têm feito parte das preocupações escolares, assim como as questões e problemas da comunidade, da cidade, do país ou do mundo só têm recebido atenção marginal" (BRASIL, 2002, p. 9-10).

Os Parâmetros Curriculares Nacionais para o Ensino Médio também destacam a importância da valorização das diferenças, a fim de evitar o nivelamento ou a normalização (FOUCAULT, 1997) dos indivíduos/alunos, processo tão comum em nossas escolas e sociedade, visto que:

\footnotetext{
As escolas devem estar conscientes de que devem promover todos os seus alunos e não selecionar alguns; que devem emancipá-los para a participação e não domesticá-los para a obediência; que devem valorizá-los em suas diferenças individuais e não nivelá-los por baixo ou pela média (BRASIL, 2002, p. 13).
}

Nessa perspectiva de normalização e nivelamento, Rios (2011b) também destaca que na escola as diferenças existentes nos sujeitos são tornadas invisíveis, considerando-se o objetivo de normalização desses seres. Dessa forma, na tentativa de romper com tal processo normalizador e homogeneizador, é preciso perceber e valorizar a vida e todo seu significado contido e trazido pelos alunos e alunas, no caso específico os da roça, para o espaço escolar, buscando integrar as vivências e o conhecimento à escola e à vida, e vice-versa, como destaca Castrogiovanni:

\begin{abstract}
Sabemos que o sujeito traz consigo uma carga de experiências e de conhecimento sistematizados ou não, realidades vividas muitas vezes impossíveis de serem representadas pelos professores. No entanto, pelo que temos discutido em diferentes encontros, cada vez mais acreditamos que tais vivências devam ser aproveitadas, problematizadas, textualizadas, buscando-se, assim, a inserção da vida na escola, tornando a escola, efetivamente, integrada à vida (CASTROGIOVANNI, 2007, p. 43).
\end{abstract}

Assim, lutamos por uma escola mais integrada à vida, que perceba, valorize, incentive e entenda o trabalho com as diferenças como o caminho para a construção de sujeitos mais autônomos e reflexivos, tanto em relação a si mesmos, quanto aos outros e ao espaço onde vivem.

\title{
3 DIÁLOGOS CONTEMPORÂNEOS SOBRE JUVENTUDES RURAIS, RITOS DE PASSAGEM E HOMOGENEIZAÇÃO
}

$\mathrm{Na}$ contemporaneidade, torna-se imprescindível discutir a escola na qualidade de espaço de homogeneização e o quanto o professor, com seus discursos e práticas, às vezes, sem perceber, participa, orienta e encaminha tal processo. Assim, entendemos a escola como um espaço da biopolítica ${ }^{\mathrm{ii}}$, local no qual, por meio de simbologias, práticas, discursos e orientações (implícitas e/ou explícitas), as subjetividades dos sujeitos ali inseridos vão sendo 
alteradas, normalizando-os, num movimento de modelagem do indivíduo e de gestão da coletividade (FOUCAULT, 1997).

Logo, percebe-se que há uma espécie de "formatação" dos jovens rurais à medida que ingressam nas escolas urbanas e de suas características individuais, que vão sendo suplantadas; os estudantes vivenciam um verdadeiro processo de metamorfose no rito de passagem escola rural/escola urbana. Além dos intensos desafios de adaptação a uma nova rotina de deslocamento, de novas práticas pedagógicas, chama-nos atenção o processo de aculturação imposto a esses jovens. Nega-se a relação desses estudantes com o espaço, com a terra, com a natureza, com a comunidade, invisibilizam-se a cultura e identidade rural nas práticas pedagógicas desenvolvidas em escola de Ensino Médio, evidenciando assim a modelagem do indivíduo para a vida na sociedade urbana, em um processo de produção da subjetividade e bloqueio da singularização (GUATTARI e ROLNIK, 1999).

Entendemos que, tendo em vista as questões levantadas até então, torna-se necessário escutar a voz dos jovens que vivenciam o processo de transição de escolas rurais para escolas urbanas, na tentativa de apreensão de como se percebem nesse processo pelas suas narrativas. Para isso, optamos por realizar entrevistas narrativas (SCHUTZE, 2010) com um grupo de alunos do Ensino Médio do Colégio Estadual Polivalente de Castro Alves - Castro Alves/BA, município do Recôncavo baiano com população estimada de 25.408 habitantes, segundo IBGE (2010). Destacamos que tal escola é a única a ofertar o Ensino Médio na cidade, possuindo um percentual de cerca de $42 \%$ de alunos provenientes da zona rural, segundo informações do Sistema de Gestão Escolar (BAHIA, 2015).

A opção pela realização de entrevistas narrativas está baseada na importância que concebemos ao método (auto)biográfico, haja vista que tal método possibilita a busca de significados das experiências de vida dos sujeitos como seres únicos, ao mesmo tempo em que também proporciona que os sujeitos se conheçam melhor, em um processo de formação e autoformação. Sobre essa questão, Nóvoa e Finger afirmam que:

O método biográfico permite que seja concedida uma atenção muito particular e um grande respeito pelos processos das pessoas que se formam: nisso reside uma das suas principais qualidades, que o distinguem, aliás, da maior parte das outras metodologias de investigação em ciências sociais. (NÓVOA e FINGER, 2014, p. 21).

Nessa perspectiva investigativa, tais entrevistas contribuem para que promovamos um diálogo com os jovens rurais que estudam em uma escola urbana, o trânsito que vivenciam entre diferentes territorialidades que fazem diariamente para estudar e o processo de subjetivação que estão sujeitos nessa trajetória, mas, sobretudo, na própria escola, pois, como afirma Delory-Momberger (2012, p. 191), "o espaço da escola (no sentido genérico do termo) e das aprendizagens parece que deve constituir um campo privilegiado da pesquisa biográfica em educação". Além disso, a autora também nos possibilita refletir como os alunos da roça se 
defrontam com o mundo social e cultural existente no ambiente escolar, implicando questionarmos - como tal processo produz metamorfoses no eu de cada aluno?

Devemos esclarecer que, por causa do compromisso ético de não identificação dos entrevistados, utilizamos pseudônimos, escolhidos pelos próprios colaboradores, nomeados como Maria, Raquel, João e Elias, garantindo a não identificação dos mesmos. Os alunos e alunas colaboradores são estudantes da $3^{\mathrm{a}}$ série do Ensino Médio da referida escola, com idades entre 17 e 18 anos. Salienta-se que todos os colaboradores estudaram em classes multisseriadas durante os Anos Iniciais do Ensino Fundamental, passando a estudar na cidade a partir dos Anos Finais do Ensino Fundamental. Neste momento estão concluindo o Ensino Médio (2015). Assim, sabemos que a escola como espaço de vida, de experiência e também de dispositivos do biopoder, já deve ter fornecido inúmeros subsídios para a (re)construção de suas identidades e representações da realidade, suplantando e/ou até negando as suas ruralidades. Nesse sentido, Delory-Momberger (2012, p. 192), nos diz: "para aqueles que o frequentam, o 'mundo da escola' constitui um espaço de vida e de experiência particular, na medida em que ele envolve instituições e contextos, procedimentos e dispositivos, papéis e relações sociais, tarefas e objetos específicos".

Tal trabalho, utilizando-se das narrativas, vem discutir as metamorfoses do eu que os alunos da roça, ao final do Ensino Médio, já passaram desde que começaram a frequentar uma escola urbana. Analisamos tal processo por intermédio das narrativas dos alunos da roça, quando afirmam que:

Não sinto vergonha de ser da roça não, gosto mais de lá, pois lá eu me sinto solto, mais livre, pois tem mais espaço, é calmo, lá eu me sinto melhor (JOÃO, 2015).

Lá é melhor, pois a gente conhece todo mundo, isso dá segurança (MARIA, 2015).

Lá é mais seguro, melhor do que aqui na cidade (ELIAS, 2015).

Os excertos das narrativas dos alunos evidenciam forte ligação com o ambiente rural, seu espaço vivido, os quais destacam maior familiaridade e liberdade. Segundo Tuan (1983, p. 3) "o lugar é segurança e o espaço é liberdade: estamos ligados ao primeiro e desejamos o outro". Além da questão do lugar, é preciso destacar também aspectos relacionados ao tempo e ao espaço no ambiente rural, os quais não seguem o mesmo ritmo no território urbano. Especialmente nas médias e pequenas propriedades rurais, na maioria das vezes, ainda são os ditames naturais que regulam a vida e o trabalho, dando mais naturalidade e liberdade aos sujeitos, enquanto que na cidade tudo é regulado e normatizado pelo e para o sistema hegemônico - capitalista - e para seu objetivo principal, o lucro e acumulação.

Mesmo assim, os alunos se sentem atraídos pelo espaço urbano, pela liberdade que este dissimuladamente simboliza, visto que: 
Estudar na cidade é uma coisa diferente, pois a gente sai um pouco da rotina, a gente fica um pouco preso lá, e aqui não, é uma diversão (RAQUEL, 2015).

Mesmo se tivesse escola na roça, eu preferiria vir aqui para a cidade, a gente já se acostumou, no dia que falta ou não tem aula, a gente sente falta (MARIA, 2015).

Nesse sentido, percebemos nas narrativas que, mesmo reconhecendo o espaço rural como melhor, se sentem, pelo menos agora, no final do Ensino Médio, mais à vontade na zona urbana, onde experimentam a liberdade. Talvez isso também seja explicado porque já tenham modificado a sua identidade, fazendo desaparecer ou diminuir, sensivelmente, a identidade rural pelo processo de normalização que vêm passando desde que começaram a estudar na escola da cidade: “a gente já se acostumou” (MARIA, 2015).

Em relação à mudança da escola da roça para a escola da cidade, ao final dos anos iniciais do Ensino Fundamental, os alunos destacaram algumas memórias e experiências, quando narram que:

Lá cada dia era uma matéria, segunda-feira: Português, terça: Matemática, quarta: Geografia, quinta: História. Aqui não, é tudo junto, tem os horários. Lá não tem, cada dia é uma matéria (MARIA, 2015).

$\mathrm{Na}$ escola da roça, era uma professora só para ensinar tudo, aqui varia de professor, temos vários professores diferentes, cada um age de forma diferente, e tem esse impasse, uma convivência maior com todos eles, e na roça já estávamos acostumados com uma professora só que era conhecida, não tinha esse peso, a gente teve que aprender a conviver com esse peso (RAQUEL, 2015).

Observamos nos excertos das narrativas de Maria e Raquel que elas destacam a mudança da rotina, tanto na prática escolar quanto nas relações entre os sujeitos na escola, e como essa mudança se reflete em "um peso", fazendo com que o aluno atravesse fronteiras e assuma outras posições e papéis diferentes daqueles que tinham antes, na escola rural. Rios (2011b) destaca essa mudança para estudar na cidade, de enxergar-se como estrangeiro em tal espaço, e que isso tudo "passa pela construção do desconhecido, do imprevisível, do incontrolável, da ausência da 'mesmidade', os quais compõem as relações com o outro, colocando a fronteira que o identifica à prova; atravessar, cruzar as fronteiras significa assumir posições híbridas" (2011b, p. 109). Os excertos a seguir explicitam tais questões, quando Elias e João afirmam que:

Quando mudei para cá, para a escola da cidade, foi difícil, pois a gente já estava acostumado com um professor tipo familiar, e aí passamos a conhecer mais pessoas. Era estranho (ELIAS, 2015).

Lá eu conhecia a professora e os colegas desde menorzinho, a gente já tinha intimidade e a convivência era mais fácil, aqui a gente não conhecia ninguém e se sentia assim, meio desconfortável (JOÃO, 2015).

João e Elias também enfatizam essa ausência da "mesmidade", mas já trazem também a questão de estar e conviver com o outro, aqueles que não são conhecidos e familiares, como \begin{tabular}{l|l|l|l|l|l|l} 
(C) ETD - Educ. Temat. Digit. & Campinas, SP & v.17 & n.3 & p. 542-557 & set./dez.2015 & ISSN 1676-2592
\end{tabular} 
ocorria na escola rural. A escola urbana é a escola da rua, do desconhecido, do estranho, do desconforto, diferente da escola rural, concebida, pela sua familiaridade, pela segurança, como se fosse uma casa (RIOS, 2011b). Todo esse processo produz metamorfose no eu, pois a experiência de aprender a conviver com o outro, o desconforto e a estranheza dessa convivência contribuem para criação de outras identidades e visões de mundo. Esta questão é sinalizada por Raquel, ao afirmar que:

Foi uma transição da infância para a adolescência. Aqui a gente começou a aprender como se comportar de forma diferente na sociedade, alguns costumes foram mudados, é uma preparação totalmente diferente daquela da escola da roça [...] Tive que mudar muitas coisas, não diria amadurecimento total, claro, pois a gente vai amadurecendo com o passar do tempo; tive que mudar algumas atitudes, meio infantis, ingênuas, que tive que deixar para trás, a gente começou a trabalhar isso, essa mudança aqui na cidade. Era mais criança um pouquinho e aqui a gente teve que crescer (RAQUEL, 2015 - Grifos nosso).

Raquel destaca a questão da transformação por que teve de passar. Essa transição gerou mudanças nos costumes, atitudes, papéis. Segundo a aluna, "a gente começou a trabalhar isso", ou seja, a metamorfose na sua identidade, a fim de assumir uma identidade mais "condizente" com aquela requerida pela escola da cidade. Enfim, ocorre uma negação da maneira de ser, estar e conceber o mundo, das suas ruralidades. A chegada à escola da cidade 'implica em um movimento de 'tornar-se', o qual delineia, para os alunos e alunas da roça, novos modos de ser e estar no mundo, novas identidades” (RIOS, 2011b, p. 137).

Uma das questões que discutimos anteriormente é se a escola está preparada para trabalhar com a diversidade, valorizando e respeitando as diferenças entre os alunos, especialmente em relação aos estudantes da roça. Sobre isso, os jovens afirmam que:

Não é que role o preconceito por a gente ser da roça, não rola, mas é que existem dificuldades até para fazer trabalho. Assim, a gente não tem acessibilidade para isso, e atrapalha, pois não temos como nos encontrar para fazer [...] Para fazer trabalho, a gente tem que se juntar na sala entre uma aula e outra para dividir as partes, pois não temos tempo de reunir depois, todo mundo mora em um lugar diferente. (RAQUEL, 2015).

A dificuldade é para fazer trabalho. A gente faz trabalho quando sai do colégio aqui, sai correndo para ir na lan house e faz. Quarta-feira mesmo a professora passou um trabalho, e o meu grupo cada um mora num lugar diferente, e teve o feriado também, e aí a gente não conseguiu fazer, pois todo mundo vive distante. Isso prejudica. E quem mora na sede não, tem mais facilidade, pois a maioria tem computador, tem acesso a internet e a gente não (ELIAS, 2015).

Tais narrativas indicam que a escola da cidade segue práticas e ritmos relacionados ao modo de vida urbano, não se importando com as múltiplas especificidades territoriais, simbólicas e subjetivas dos seus alunos, mesmo quando quase a metade desses alunos são da zona rural $-42 \%$ é o índice de alunos da zona rural no colégio pesquisado. Os professores, a Coordenação Pedagógica e a Direção seguem, no planejamento e ações pedagógicas, as 
referências e lógicas urbanas e o aluno da roça tem que se adaptar de qualquer forma a tal realidade, a fim de que possa avançar na aprendizagem e nas séries.

Apesar da narrativa de Raquel afirmar que não há preconceito por ser da roça, Maria (2015) destaca que 'tem umas brincadeiras que rolam: 'Ah, vocês são da roça!' Mas isso não me incomoda não". Mesmo afirmando que não incomode, sabemos que em nossa sociedade sentir-se diferente dos demais é visto como algo negativo, principalmente se o indivíduo possui características que abalam a autoestima, como atrasado e inferior. Dessa forma, tais alunos são levados a pensar, agir e ser iguais aos demais, enquadrados a partir de normas que alteram as suas identidades.

Outra questão destacada nas narrativas pelos colaboradores é que os alunos da roça possuíam grande vontade de vir estudar na escola da cidade, pois a questão do novo, da aventura, da diversão de ir e vir no ônibus todos os dias era motivo de expectativa e ansiedade:

Quando a gente via todo mundo descendo do ônibus, a gente se perguntava: quando é que a gente vai estudar na cidade? (RAQUEL, 2015).

No último ano da escola lá na roça, a gente tem uma vontade logo de vir estudar aqui, conhecer como é a rotina, o novo (JOÃO, 2015).

Porém, observamos que a escola da cidade não aproveita tal ansiedade e expectativa dos alunos de conhecer o novo, direcionando esses sentimentos a favor da construção do conhecimento e do sujeito; pelo contrário, todo esse potencial é negado, anulado ou desperdiçado, a fim de que o aluno assuma a identidade urbana, mais condizente com a escola onde agora está. Segundo Rios (2011a, p. 133), "especificamente para os alunos e alunas da roça, a escola da cidade não se organiza para acolhê-los, aceitando seus saberes, discursos, identidades que não se deixam circunscrever nos limites escolares".

Mais uma vez, notamos que tais alunos, além de invisibilizados, têm suas referências negadas e até substituídas pelos discursos e práticas que acontecem na escola, que vão subsidiar a normalização do sujeito, o seu enquadramento aos ditames da escola e da sociedade urbana, tal como afirmam João e Raquel.

Era muito tímido, porque lá eu conhecia todo mundo, e não falava com gente desconhecida, aqui eu tive que mudar, me soltar mais, não estou mais muito tímido como era (JOÃO, 2015).

Realmente, esse negócio da timidez, de mudar o interior, foi muito importante, na roça era uma coisa completamente diferente, a gente convivia mais com outras crianças na mesma sala, a convivência que a gente tinha era maior, aqui passamos a conviver com pessoas da nossa idade ou até mais velhas, aí tem um peso mais de estar se soltando, se envolvendo com essas pessoas, a gente teve que trabalhar bastante isso na gente (RAQUEL, 2015). 
Os excertos das narrativas de João e Raquel revelam modos de adaptação a outra realidade, modificando alguns hábitos, atitudes e também superando algumas limitações e medos. Tal metamorfose exige grande esforço interior: "a gente teve que trabalhar bastante isso na gente" (RAQUEL, 2015). A fim de se adequar à norma da escola e das sociedades urbanas e torna-se um sujeito normalizado, controlado pela biopolítica (FOUCAULT, 1997), presente nos discursos e nas práticas dos professores e da escola. Nessa perspectiva, Rios (2011a), ratifica a discussão, afirmando que os alunos da roça ao chegarem à escola da cidade:

[...] são posicionados diante da identidade de 'ser da roça' para adquirirem outra identidade de aluno e aluna da escola da cidade. Assim, essas práticas discursivas regulam fazeres, dizeres, saberes dos alunos e alunas da roça uma vez que, em uma perspectiva foucaultina, tornam-se dispositivos de governo e controle que determinam e produzem as identidades desses sujeitos (RIOS, 2011a, p. 133).

Como pudemos observar, os discursos, práticas e dispositivos do biopoder existentes na escola servem para normalizar os sujeitos, invisibilizar e negar as diferenças, apagando suas referências de vida e percepção do mundo, ou seja, suas ruralidades. Nesta perspectiva, destacamos o quanto o descuido e o desrespeito a uma vida, seus modos de ser e estar no mundo podem comprometer tanto o futuro desse sujeito quanto toda a teia da vida a que ele esteja ligado.

\section{POR UM ENSINO MÉdIO PARA ALÉM DOS DITAMES DO MERCADO: ALGUMAS (IN)CONCLUSÕES}

Esse texto insere-se em uma temática silenciada e pouco visibilizada nas produções acadêmicas - a dos ritos de passagem de estudantes de escolas de áreas rurais para as escolas da cidade. Em notas (in)conclusivas, ressaltamos neste artigo a necessidade de mais estudos sobre questões aqui levantadas, na tentativa de rompermos silêncios e práticas pedagógicas ancoradas em processos de subjetivação normalizantes (GUATTARI e ROLNIK, 1999).

Nessa perspectiva, os estudos sobre os ritos de passagem tornam-se essenciais e, para melhor entendimento dessa questão, dialogamos com Van Gennep (2008), que concebe o rito como representação de uma transformação, a partir do qual o sujeito deixa de ser o que era para ser outra coisa em potência e apresenta ainda o risco da reflexão, pois neste momento o sujeito reflete sobre o seu papel em um determinado grupo social, seus valores e questões morais, para seguir no processo de agregação de uma nova identidade. Para este autor, o rito se divide em três movimentos, a separação (que é o rito propriamente dito), a margem (o entre-rito e o imediatamente pós-rito, o liminar) e a agregação (a nova identidade pós-rito). Os ritos de passagem marcam, do ponto de vista simbólico, uma transição social, implicando 
novas disposições sobre a formação dos sujeitos ou modos de enfrentamento e negação por parte dos mesmos, evidenciados pelas marcas da passagem.

Concluímos que os jovens rurais chegam às escolas urbanas cheios de expectativas e anseios, buscando uma qualidade de vida melhor, o que para eles significa a saída da roça para cursar o Ensino Médio nas cidades, à medida que, na maioria dos municípios, tal nível, atribuição legal dos estados, só é ofertado nos centros urbanos. $\mathrm{O}$ fato de frequentarem uma escola regida a partir de referências urbanas, onde suas maneiras de ser, agir e perceber o mundo, ou seja, suas ruralidades, são invisibilizadas e/ou negadas, gera uma metamorfose nas suas identidades e até nos seus sonhos, pois deles exige-se que assumam uma identidade única e normalizada. O que ratifica o que já foi dito a respeito da produção da subjetividade, pois a "máquina capitalística produz [...] aquilo que acontece quando nós sonhamos, quando devaneamos, quando fantasiamos" (GUATARRI e ROLNIK, 1999, p. 22).

Dessa forma, observa-se que os estudantes colaboradores da pesquisa buscam o Ensino Médio, submetendo-se aos ditames do mercado, para conseguir um emprego que possa fazer com que eles consigam se projetar para fora do campo e das áreas rurais, movidos pelo desejo de se inserirem, de forma mais intensa, na sociedade do consumo. Entendendo, como Deleuze e Guattari (1995), o desejo como força motriz de construção da sociedade, que se forma em nível inconsciente, esses jovens vão operar na construção e desconstrução de seus mundos, na metamorfose dos seus territórios existenciais.

Evidenciamos o quanto a escola configura-se como espaço dessa homogeneização, tornando-se necessário repensar as práticas pedagógicas desenvolvidas, sobretudo nas escolas de Ensino Médio, que acolhem estudantes egressos de escolas rurais a fim que de que a educação para eles possa ser mais acolhedora e emancipatória, em vez de homegeneizadora e castradora. É preciso uma escola que valorize as múltiplas identidades dos sujeitos, seus modos de ser, existir e apreender a realidade para que ocorra a formação de sujeitos mais autônomos e reflexivos, tanto sobre si mesmos, quanto em relação aos outros e ao mundo que os rodeiam.

Acreditamos que a persistência no desenvolvimento de novas pesquisas e na criação de ações e propostas didático-pedagógicas mais inclusivas e acolhedoras para os estudantes da roça nas escolas urbanas favorecerá a configuração de um "novo" rural, que fuja dos estereótipos do campo como local de atraso, o que ajudará também na construção de uma "nova" escola, com professores que tenham como principal desafio perceber e valorizar a vida nesse espaço, à medida que o mundo, o lugar, nossas experiências e nossas histórias estejam dentro de nós e formem a teia da nossa vida, não devendo nunca ser negligenciadas ou desrespeitadas.

Pelo contrário, é preciso incentivar o sujeito a investir nos processos de formação e autoformação, projetando-se em um movimento de devir - entendendo devir como ruptura, 
principalmente com o modelo dominante do homem branco, adulto, europeu, racional, morador dos grandes centros urbanos. A experimentação do devir não se dá no nível do imaginário, dos sonhos; é produção de territórios singulares que criamos (no sentido discutido por Guattari [1999]). E é em uma educação emancipatória e na produção de territórios singulares que apostamos para essas juventudes rurais que adentram nas escolas urbanas.

\section{REFERÊNCIAS}

ASSMANN, Hugo. Reencantar a educação: rumo à sociedade aprendente. Petrópolis: Vozes, 2003.

BAHIA. Sistema de Gestão Escolar (SGE). [Percentual de matrículas do Colégio Estadual Polivalente de Castro Alves]. Secretaria da Educação do Estado da Bahia, 2015.

BRASIL. Ministério da Educação - Secretária de Educação Média e Tecnológica. PCN+ ensino médio: Orientações Educacionais Complementares aos Parâmetros Curriculares Nacionais. Brasília: MEC; SEMTEC, 2002.

CASTROGIOVANNI, Antonio Carlos. Para entender a necessidade de práticas prazerosas no ensino de geografia na pós-modernidade. In: REGO, Nelson; CASTROGIOVANNI, Antonio Carlos; KAERCHER, Nestor André (Org.). Geografia: práticas pedagógicas para o ensino médio. Porto Alegre: Artmed, 2007, p. 35-47.

DELEUZE, Gilles e GUATTARI, Félix. Mil Platôs: capitalismo e esquizofrenia. Tradução de Aurélio Guerra Neto e Ana Lúcia de Oliveira. Rio de Janeiro: Editora 34, 1995.

DELORY-MOMBERGER. A pesquisa biográfica em educação: desafios e perspectivas. In: SOUZA, Elizeu Clementino de. (Org.). Educação e ruralidades: memórias e narrativas (auto) biográficas. Salvador: EDUFBA, 2012, p. 181-200.

FOUCAULT, Michel. Resumo dos cursos do Collége de France (1970-1982). Tradução Andréa Daher. Rio de Janeiro: Jorge Zahar, 1997.

GUATTARI, Félix. Da produção de subjetividade. In: PARENTE, André. (Org.). Imagemmáquina: a era das tecnologias do virtual. Rio de Janeiro: Editora 34, 1993, p. 177-191.

GUATTARI, Félix; ROLNIK, Suely. Micropolítica: cartografias do desejo. Petrópolis: Vozes, 1999.

IBGE. Evolução da população de Castro Alves/BA. Censo demográfico 2010. Disponível: 〈http://goo.gl/ZDvO39> . Acesso em: 26 jun. 2015. 
NÓVOA, Antonio; FINGER, Mathias (Orgs.). O método (auto) biográfico e a formação. Natal: EDUFRN; São Paulo: Paulos, 2014.

RIOS, Jane Adriana Vasconcelos Pacheco. Professores da cidade, alunos da roça: identidades e discursos na escola. Educação e Contemporaneidade, Salvador, BA, v. 20, n. 36, p. 127136. jul./dez. 2011a. Disponível em: 〈http://goo.gl/ZbXlxz〉. Acesso em: 08 jul. 2015. ISSN 2358-0194.

RIOS, Jane Adriana Vasconcelos Pacheco. Ser e não ser da roça, eis a questão! Identidades e discursos na escola. Salvador: EDUFBA, 2011b.

SANTOS, Milton. O espaço do cidadão. 7. ed., São Paulo: Editora da Universidade de São Paulo, 2012.

SCHÜTZE, Fritz. Pesquisa biográfica e entrevista narrativa. In: PFAFF, Nicolle; WELLER, Wivian (Orgs.). Metodologias da pesquisa qualitativa em Educação: teoria e prática. Vozes: Petrópolis, 2010. p. 210-222.

SOUZA, Elizeu Clementino de (Coord.). Multisseriação e trabalho docente: diferenças, cotidiano escolar e ritos de passagem. Salvador: UNEB; FAPESB, 2013.

SOUZA, Elizeu Clementino de. A caminho da roça: olhares, implicações e partilhas. In: SOUZA, Elizeu Clementino de. (Org.). Educação e ruralidades: memórias e narrativas (auto) biográficas. Salvador: EDUFBA, 2012, p. 17-28.

SOUZA, Elizeu Clementino de. Territórios das escritas do eu: pensar a profissão - narrar a vida. Educação, Porto Alegre, RS, v. 34, n. 2, p. 213-220. maio/ago. 2011a. Disponível em: < http://goo.gl/spBQaB>. Acesso em: 08 jul. 2015. ISSN 1981-2582.

SOUZA, Elizeu Clementino de. Educação e ruralidades: olhares cruzados sobre ruralidades contemporâneas. In: Educação e Contemporaneidade, Salvador, BA, v. 20, n. 36, p. 15-18. jul./dez. 2011b. Disponível em: 〈http://goo.gl/IMZdZs >. Acesso em: 08 jul. 2015.

ISSN 2358-0194.

SOUZA, Elizeu Clementino de. A formação como processo de conhecimento: histórias de vida e abordagem (auto) biográfica. In.: BRAGANÇA, Inês Ferreira de Souza; ARAÚJO, Mairce da Silva; ALVARENGA, Márcia Soares; MAURÍCIO, Lúcia Velloso. Vozes da Educação: memórias, histórias e formação de professores. Rio de Janeiro: DP et alli, 2008, p. 85-102.

SOUZA, Elizeu Clementino de. O conhecimento de si: estágio e narrativas de formação de professores. Salvador: UNEB; Rio de Janeiro: DP\&A, 2006.

TRINDADE, Azoilda Loretto da. Olhando com o coração e sentindo com o corpo inteiro no cotidiano escolar. In: TRINDADE, Azoilda Loretto da; SANTOS, Rafael dos. (org.). Multiculturalismo: mil e uma faces da Escola. 2. ed. Rio de Janeiro: DP\&A, 2000, p. 7-16. 
TUAN, Yi-Fu. Espaço e lugar: a perspectiva da experiência. Tradução de Lívia de Oliveira. São Paulo: Difel, 1983.

VAN GENNEP, A. Los ritos de paso. Madrid: Alianza Editorial, 2008.

\section{Notas}

i Tal projeto é desenvolvido e coordenado pelo Grupo de Pesquisa (Auto)biografia, Formação e História Oral, da Universidade do Estado da Bahia (GRAFHO/UNEB), em parceria com os grupos Diversidade, Narrativas e Formação (DIVERSO/UNEB), Educação do Campo e Contemporaneidade (UNEB), Currículo, Avaliação e Formação, da Universidade do Recôncavo da Bahia (CAF/UFRB) e o Laboratório EXPERICE (Paris 13/Paris8), sendo financiado pela Fundação de Amparo à Pesquisa do Estado da Bahia (FAPESB), no âmbito do Edital 028/2012 - Prática Pedagógicas Inovadoras em Escolas Públicas e do MCTI/CNPq, Chamada Universal $n^{0}$. $14 / 2014$.

ii Biopolítica é o termo utilizado por Foucault (1997) para designar a forma na qual o poder tende a se modificar no final do século XIX e início do século XX. As práticas disciplinares utilizadas antes visavam governar o indivíduo. A biopolítica tem como alvo o conjunto dos indivíduos, a população.

Como citar este documento:

SOUZA, Elizeu Clementino de Souza; SOUZA, Hanilton Ribeiro de; ORRICO, Nanci Rodrigues.

Metamorforses do eu: estudantes rurais nas escolas urbanas. ETD - Educação Temática Digital, Campinas, SP, v. 17, n. 3, nov. 2015. ISSN 1676-2592. Disponível em:

<http://periodicos.sbu.unicamp.br/ojs/index.php/etd/article/view/8638272>. Acesso em: 16 dez. 2015. 